\title{
Decreased expression of Dkk1 and Dkk3 in human clear cell renal cell carcinoma
}

\author{
CHANG-CHENG GUO ${ }^{1 *}$, XIAO-LONG ZHANG ${ }^{1,2^{*}}$, BIN YANG $^{1,2}$, \\ JIANG GENG ${ }^{1,2}$ BO PENG ${ }^{1,2}$ and JUN-HUA ZHENG ${ }^{1,2}$ \\ ${ }^{1}$ Department of Urology, Shanghai Tenth People's Hospital, Tongji University, Shanghai 200072; \\ ${ }^{2}$ Department of First Clinical Medical College, Nanjing Medical University, Nanjing, Jiangsu 210029, P.R. China
}

Received July 17, 2013; Accepted March 6, 2014

DOI: $10.3892 / \mathrm{mmr} .2014 .2077$

\begin{abstract}
The expression patterns of the Dickkopf (Dkk) family of proteins varies in different cancers. In the present study, the expression levels of Dkk1 and Dkk3 were investigated in clear cell renal cell carcinoma (ccRCC) tissues. Dkk1 and Dkk3 serum levels were also examined in patients with ccRCC, and the association between clinicopathological features and Dkk levels was investigated. Serum Dkk1 and Dkk3 were quantified using ELISA in 64 patients with ccRCC and in 30 healthy individuals (controls). The expression levels of Dkk1 and Dkk3 were analyzed in tumor and adjacent normal tissues obtained from patients with ccRCC $(n=20)$ using quantitative polymerase chain reaction (qPCR), western blot analysis and immunohistochemistry. The mean serum levels of Dkk1 and Dkk3 in the patients with ccRCC were significantly lower than those in the healthy controls. Furthermore, the serum Dkk1 levels were significantly lower at higher tumor-node-metastasis stages and tumor grades. qPCR, western blot analysis and immunohistochemistry revealed a significant decrease in the Dkk1 and Dkk3 mRNA and protein levels in the tumor tissues compared with the adjacent normal tissues. Consequently, Dkk1 and Dkk3 may present a novel molecular target for the diagnosis and therapeutic treatment of ccRCC.
\end{abstract}

\section{Introduction}

The incidence of renal cell carcinoma (RCC) has increased worldwide over the past three decades. Global estimates in 2008 indicated that 209,000 new cases were being diagnosed each year (1). RCC is heterogeneous and comprises several histological types, which have different genetic and clinicopathological features that determine clinical course and outcome.

Correspondence to: Professor Jun-hua Zheng, Department of Urology, Shanghai Tenth People's Hospital, Tongji University, 301 Yanchang Road Shanghai, Shanghai 200072, P.R. China

E-mail: greatwal1063030@126.com

*Contributed equally

Key words: Dkk1, Dkk3, Wnt, clear cell renal cell carcinoma
Clear cell RCC (ccRCC), also called conventional RCC, is the most common histological type of RCC, representing $~ 80 \%$ of cases (2). Despite the development of imaging techniques and surgical innovations, ccRCC carries an extremely high risk of invasiveness and metastasis, with $50 \%$ of patients eventually developing metastatic disease (3). Furthermore, ccRCC exhibits resistance to chemotherapy and radiation, and only $\sim 10 \%$ of patients suffering from metastatic disease survive for five years following diagnosis (4). As a result, an enhanced understanding of the molecular pathogenesis of ccRCC is required for the development of novel diagnostic methods and therapeutic strategies.

Wnts are a family of cysteine-rich, secreted glycoproteins with functions in numerous cellular processes, including embryogenesis and oncogenesis, the induction of cell polarity, the maintenance of tissue homeostasis and cell growth control. The Wnt signaling pathway is composed of canonical Wnt signaling via $\mathrm{Wnt} / \beta$-catenin and non-canonical Wnt signaling via the $\mathrm{Wnt} / \mathrm{Ca}^{2+}$ pathway and Wnt/c-Jun N-terminal kinase (5). Deregulation of canonical Wnt signaling has been indicated for a variety of types of human cancer and other diseases (6). Activation of this signal cascade is a complex process; Wnt ligands bind to their cognate Frizzled (Fz)/Low-density lipoprotein receptor-related protein (Lrp) receptor complex and relay a signal via cytoplasmic transduction intermediates to $\beta$-catenin. A number of extracellular Wnt antagonists modulate the activity of this signaling cascade. Members of the secreted Fz-related protein (Sfrp) family and Wnt-inhibitory factor-1 (Wif-1) directly sequester Wnt ligands, whereas members of the Dickkopf (Dkk) family of proteins interfere with the co-receptors Lrp and Kremen (Krm), leading to the internalization of Lrp, and thus preventing Wnt from binding to a functional receptor complex (7).

Of the four known mammalian Dkk members, Dkk1 is the most studied, and has been demonstrated to be an antagonist of the canonical Wnt signaling pathway. By contrast, Dkk3 is the most divergent member of the human Dkk family and does not modulate Wnt signaling (8). Furthermore, it has been indicated that Dkk3 has an important role in tumor suppression, and therefore may represent a notable therapeutic target against aberrant Wnt signaling in the treatment of human cancer. Dkk1 and Dkk3 expression has been investigated in numerous tumors, including hepatocellular carcinomas (9), Wilms' tumors (10), pancreatic adenocarcinomas (11), ovarian (12) and colorectal (13) 
cancer, melanoma cells (14) and lung cancer (15). Dkk expression in RCC has also been investigated by Ueno et al (16) and Urakami et al (17). Ueno et al (16) studied the potential epigenetic mechanisms regulating Dkk3 expression in RCC cells and demonstrated that the mRNA expression of Dkk3 was regulated by histone modifications. The study also found that Dkk3 inhibited renal cancer growth through modulation of the cell cycle and apoptotic pathways. Urakami et al (17) demonstrated that the methylation levels of all Wnt antagonists, including sFRP-1, sFRP-2, sFRP-4, sFRP-5, Wif-1 and Dkk3, were significantly higher in RCC tissues compared with normal renal tissues. However, the expression levels of Dkk1 and Dkk3 in ccRCC, the correlation between the two proteins, and whether Dkk1 and Dkk3 contribute to the diagnosis and treatment of ccRCC have not yet been investigated. The present study investigated the serum levels of Dkk1 and Dkk3 in ccRCC patients, the correlation between Dkk1 and Dkk3, the expression of Dkk1 and Dkk3 in ccRCC tissue samples, and the correlation with the clinicopathological characteristics by statistical analysis.

\section{Materials and methods}

Patients, serum samples and tissue specimens. The selection criteria for the patients with ccRCC were as follows: i) Pathologically confirmed ccRCC; ii) a nephrectomy performed in Shanghai Tenth People's Hospital (Shanghai, China) without pre-operative adjuvant therapy, including radiotherapy or chemotherapy, and with complete clinical data; and iii) no previous history of other types of cancer. The selection criteria for the controls were as follows: i) Diagnosis of ureteral stones or urethral caruncles; ii) no disease of the vital organs, including the heart, liver and lung; and iii) no family history of cancer.

A fasting blood sample was taken from all participants, and serum was collected and stored at $-80^{\circ} \mathrm{C}$. All samples were collected prior to surgery. Pairs of cancerous and adjacent normal tissues were obtained from 20 patients with ccRCC following radical nephrectomy and once written, informed consent had been obtained from each patient. The demographic and pathological data, including age, gender and tumor stage, were obtained by a review of the patients' medical records (the data were used with the consent of the patients and with the approval of the Ethics Committee of Tongji University, Shanghai, China). Tumor stage was determined according to the 2009 tumor-node-metastasis (TNM) staging classification system and American Joint Committee on Cancer (AJCC), and tumor grade was determined according to the Fuhrman classification system (well-differentiated, grades I and II; moderately-differentiated, grade III; and poorly-differentiated, grade IV) $(18,19)$. For statistical evaluations, grades I and II tumors were considered as low-grade and grades III and IV as high-grade. Similarly, stage III and IV tumors were considered in the advanced-stage category. From the 20 tissue samples collected, 6, 8 and 10 samples were analyzed using immunohistochemistry, western blot analysis and quantitative polymerase chain reaction (qPCR) analysis, respectively.

ELISA. Dkk1 and Dkk3 were measured using an ELISA kit (Miltenyi Biotec, Bergisch Gladbach, Germany) in accordance with the manufacturer's instructions. The optical density (OD) at $450 \mathrm{~nm}$ was determined. A standard curve was established using $\mathrm{OD}_{450}$ as the $\mathrm{y}$ axis and the concentration of a standard substance as the $\mathrm{x}$ axis, and from this standard curve the level of protein was determined. Results are presented as the concentration of Dkk1 or Dkk3 (ng/ml) in samples.

Immunohistochemistry. Immunostaining was performed on paraffin-embedded $4-\mu \mathrm{m}$ sections of formalin-fixed tumor tissues, placed on chrome alum gelatin-coated glass slides and dried for $30 \mathrm{~min}$ at $70^{\circ} \mathrm{C}$. Following rehydration, the tissue sections were incubated in $3 \%$ hydrogen peroxide (Bio Basic Inc, Amherst, NY, USA) to inhibit endogenous peroxidase activity. Following citrate buffer antigen retrieval, the sections were blocked by incubation in $5 \%$ bovine serum albumin (BSA) in phosphate-buffered saline (PBS) (Bio Basic Inc). Expression of Dkk1 and Dkk3 was assessed using goat anti-human Dkk1 monoclonal antibody and rabbit anti-human Dkk3 monoclonal antibody (Abcam, Cambridge, UK) at a 1:50 dilution.

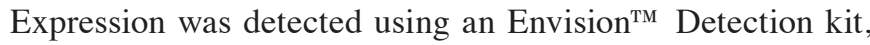
(peroxidase/DAB, rabbit/mouse; Gene Tech, Shanghai, China) in accordance with the manufacturer's instructions. The slides were then stained with DAB, washed, counterstained with hematoxylin, dehydrated, treated with xylene and mounted.

$q P C R$ analysis. Total RNA was extracted from the tissues using TRIzol reagent (Invitrogen, Carlsbad, CA, USA) in accordance with the manufacturer's instructions, and was then used for the synthesis of first-strand complementary DNA (cDNA) using the PrimeScript ${ }^{\circledR} 1$ st Strand cDNA Synthesis kit (Takara Bio, Inc., Shiga, Japan). A total of $1 \mu$ l reverse transcription (RT) product was then used as the template to amplify specific Dkk1 and Dkk3 fragments. Primers for human Dkk1, Dkk3 and $\beta$-actin genes were designed using Primer Express 2.0 software (Applied Biosystems, Inc., Foster City, CA, USA) and synthesized by Sangon (Shanghai, China). The primer sequences used were as follows: Dkk1 forward, 5'-ATTCCAACGCTATCAAGAACC-3' and reverse, 5'-CCAAGGTGCTATGATCATTACC-3'; Dkk3 forward, 5'-AGGACACGCAGCACAAATTG-3' and reverse, 5'-CCAGTCTGGTTGTTGGTTATCTT; $\beta$-actin forward, 5'-GGAGTCCTGTGGCATCCACG-3' and reverse, 5'-CTA GAAGCATTTGCGGTGGA-3'. qPCR was performed in triplicate for each sample in a $20 \mu \mathrm{l}$ reaction mixture, containing $2 \mu 1$ template DNA, $1 \mu 1$ primers, $10 \mu 1$ SYBR premix and $7 \mu \mathrm{ldd} \mathrm{H}_{2} \mathrm{O}$, using an ExScript Real-time PCR kit (Takara Bio, Inc.). PCR was performed in a 7900HT Fast Real-Time PCR machine (Applied Biosystems, Inc.) under the following conditions: $95^{\circ} \mathrm{C}$ for $30 \mathrm{sec}$, then 40 cycles of $95^{\circ} \mathrm{C}$ for $5 \mathrm{sec}$ and $60^{\circ} \mathrm{C}$ for $30 \mathrm{sec}$. Gene expression was presented using a modification of the $2^{-\Delta \Delta C t}$ method, first described by K. Livak in PE Biosystems Sequence Detector User Bulletin 2 (20).

Western blot analysis. Total protein was extracted using lysis buffer. The protein concentration was determined using the bicinchoninic acid protein assay kit (Pierce Biotechnology, Inc., Rockford, IL, USA). Equal quantities of protein were loaded on each lane and electrophoresed on SDS-polyacrylamide gels with tris-glycine running buffer, prior to being transferred to nitrocellulose membranes. Blots were saturated with $5 \%$ skimmed milk and $0.1 \%$ Tween in Tris-buffered saline, and incubated with antibodies against Dkk1 (1:200), Dkk3 (1:200) 
Table I. Clinical characteristics of the patients with ccRCC and the controls.

\begin{tabular}{|c|c|c|c|}
\hline Variables & Patients, n (\%) & Controls, n (\%) & P-value \\
\hline Total subjects & $64(100)$ & $30(100)$ & \\
\hline \multicolumn{4}{|l|}{ Age in years } \\
\hline$<45$ & $19(30)$ & $9(30)$ & \\
\hline $45-65$ & $24(37)$ & $9(30)$ & \\
\hline$>65$ & $21(33)$ & $12(40)$ & \\
\hline Average & $62.1 \pm 13.2$ & $59.8 \pm 12.2$ & 0.281 \\
\hline \multicolumn{4}{|l|}{ Gender } \\
\hline Male & $38(59)$ & $17(57)$ & 0.323 \\
\hline Female & $26(41)$ & $13(43)$ & \\
\hline \multicolumn{4}{|l|}{ TNM } \\
\hline T1 29 (45) & - & & \\
\hline T2 21 (33) & - & & \\
\hline T3 8 (13) & - & & \\
\hline T4 6 (8) & - & & \\
\hline N049 (77) & - & & \\
\hline N1 11 (17) & - & & \\
\hline N24 (6) & - & & \\
\hline M0 & $57(87)$ & - & \\
\hline M1 & $7(13)$ & - & \\
\hline \multicolumn{4}{|l|}{ Fuhrman } \\
\hline I & $28(44)$ & - & \\
\hline II & $20(31)$ & - & \\
\hline III & 12 (19) & - & \\
\hline IV & $4(6)$ & - & \\
\hline \multicolumn{4}{|l|}{ AJCC } \\
\hline I & $22(34)$ & - & \\
\hline II & $21(33)$ & - & \\
\hline III & $15(23)$ & - & \\
\hline IV & $6(10)$ & - & \\
\hline
\end{tabular}

Results for average age are presented as the mean \pm standard deviation. ccRCC, clear cell renal cell carcinoma; AJCC, American Joint Committee on Cancer staging system.

and $\beta$-actin $(1: 1,000)($ Abcam). $\beta$-actin was used as a control. The membranes were washed and then incubated with biotinylated secondary antibody labeled with horseradish peroxidase (1:1,000; Amersham Pharmacia Biotech, Amersham, UK) for $1 \mathrm{~h}$ at $37^{\circ} \mathrm{C}$, washed again and developed using an enhanced chemiluminescence (ECL) western blotting system. Membranes were then apposed to autoradiographic films (Amersham Hyperfilm ECL, Buckinghamshire, UK).

Statistical analysis. Statistical analyses were performed using SPSS 13.0 statistical software (SPSS, Inc., Chicago, IL, USA) and GraphPad Prism 5 (GraphPad Software, Inc., La Jolla, CA, USA). Data are presented as the mean \pm standard deviation and analyzed using independent t-tests. $\mathrm{P}<0.05$ was considered to indicate a statistically significant difference.

\section{Results}

Clinicopathological characteristics of the selected patients. A total of 64 patients with ccRCC and 30 controls, who were recruited from the Department of Urology, Shanghai Tenth
People's Hospital between July 2010 and June 2012, were included in this study. The mean age was $62.1 \pm 13.2$ years for the ccRCC group and 59.8 \pm 12.2 years for the control group $(\mathrm{P}=0.281)$. The clinical characteristic of the 64 patients with ccRCC and the 30 controls are summarized in Table I.

ELISA assay. Serum Dkk1 levels were found to be significantly lower in the patients with ccRCC compared with the controls. The mean serum Dkk1 level was $3.26 \pm 0.81 \mathrm{ng} / \mathrm{ml}$ in the ccRCC group compared with $5.81 \pm 1.38$ in the control group $(\mathrm{P}<0.0001)$ (Fig. 1A). Furthermore, serum Dkk1 levels were significantly lower at higher TNM stages $(2.64 \pm 0.74 \mathrm{ng} / \mathrm{ml})$ and higher tumor grades $(2.70 \pm 0.79 \mathrm{ng} / \mathrm{ml})$ compared with lower TNM stages $(3.58 \pm 0.66 \mathrm{ng} / \mathrm{ml}, \mathrm{P}<0.001)$ and lower tumor grades $(3.44 \pm 0.74 \mathrm{ng} / \mathrm{ml}, \mathrm{P}=0.003)$ (Fig. $1 \mathrm{C}$ and D). Similarly, serum Dkk3 levels were significantly lower in the patients with ccRCC compared with the controls. The mean serum Dkk3 level was $5.26 \pm 1.31 \mathrm{ng} / \mathrm{ml}$ in the ccRCC group compared with $9.11 \pm 1.55 \mathrm{ng} / \mathrm{ml}$ in the control group $(\mathrm{P}<0.0001)$ (Fig. 1B). However, no significant difference was found in Dkk3 levels between lower and higher TNM stages (5.35 \pm 1.34 and 
A

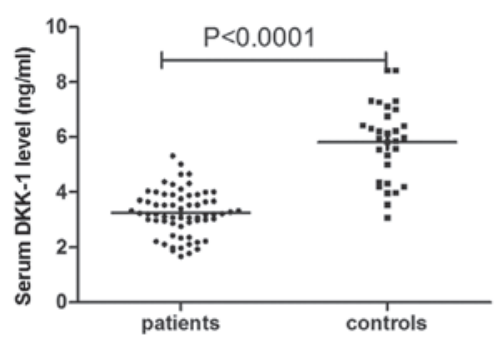

C

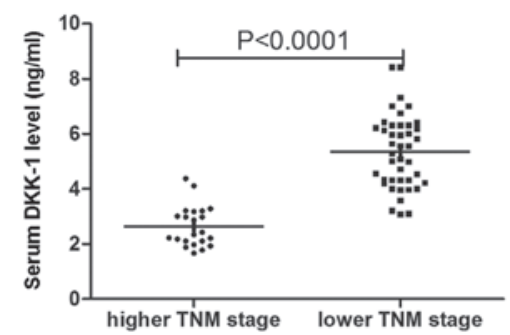

E

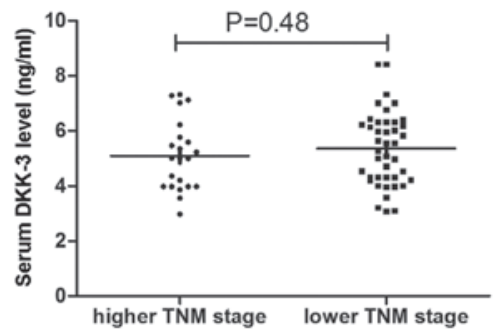

B

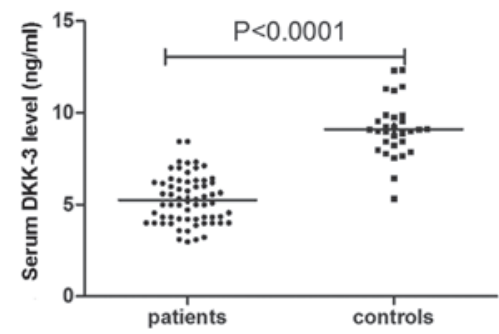

D

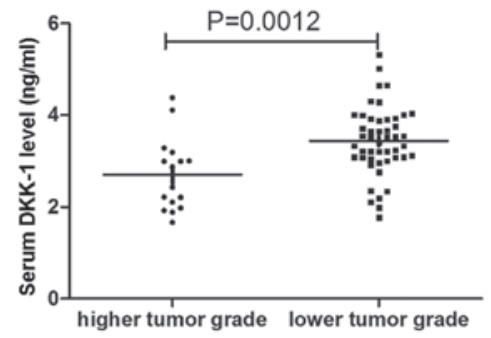

F

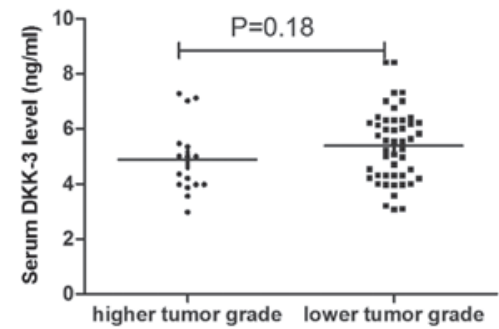

Figure 1. Serum Dickkopf (Dkk)1 and Dkk3 expression levels. (A and B) Serum Dkk1 and Dkk3 levels in patients with clear cell renal cell carcinoma (ccRCC) and controls. (C and D) Association between serum Dkk1 levels and pathological characteristics. (E and F) Association between serum Dkk3 levels and pathological characteristics. TNM, tumor-node-metastasis.

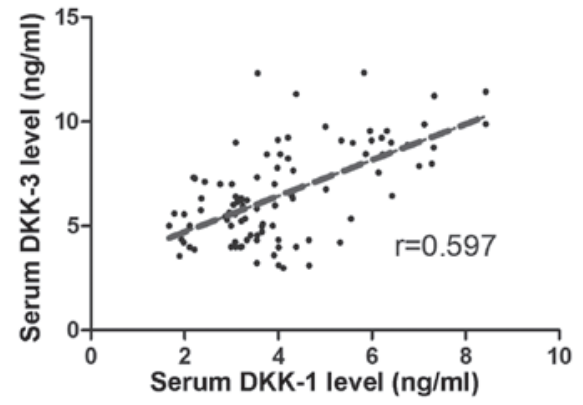

Figure 2. Correlation between Dickkopf (Dkk)1 and Dkk3.

$5.10 \pm 1.28 \mathrm{ng} / \mathrm{ml}$ respectively; $\mathrm{P}=0.482)$ and lower and higher tumor grades $(5.39 \pm 1.30$ and $4.89 \pm 1.30 \mathrm{ng} / \mathrm{ml}$, respectively; $\mathrm{P}=0.183$ ) (Fig. 1E and F).

The correlation between Dkk1 and Dkk3 serum levels in patients was measured using a correlation analysis, and the results revealed a positive correlation $(r=0.597)$ (Fig. 2).

Immunohistochemistry analysis. Immunochemistry was performed to analyze the protein expression of Dkk1 and Dkk3 in tumor and adjacent healthy tissues obtained from six patients with ccRCC (Table II). It was observed that there was a significant decrease in the expression of Dkk1 in the tumor tissue compared with the adjacent normal tissue. The same result was observed for DKK3 expression, with a significant decrease in the expression in the tumor tissue compared with adjacent normal tissue (Fig. 3).

Western blot analysis. Western blot analysis was performed to analyze the protein expression of Dkk1 and Dkk3 in samples of tumor and adjacent normal tissue obtained from eight patients with ccRCC. Western blot analysis revealed that the protein expression of Dkk1 was higher in the adjacent normal tissue compared with the tumor tissue. Low protein expression levels of Dkk1 were found in $75 \%$ (6/8) of the tumor tissues. The expression of Dkk3 was also higher in the adjacent normal tissue compared with the tumor tissue. Lower expression levels of Dkk3 were found in 62.5\% (5/8) of the tumor tissues (Fig. 4).

qPCR analysis. qPCR was performed to assess Dkk1 and Dkk3 mRNA expression in 10 tumor samples and the corresponding adjacent normal tissues. A decrease in the expression levels of Dkk1 mRNA in the tumor tissue compared with the adjacent normal tissue was observed in $70 \%$ of the samples (Fig. 5A). Consistently, $80 \%$ of samples showed a decrease in the expression levels of Dkk3 mRNA in the tumor tissue compared with the adjacent normal tissue (Fig. 5B). These results demonstrated that the average expression levels of Dkk1 and Dkk3 mRNA in tumor tissues are significantly lower than the expression levels in corresponding adjacent normal tissues. 
Table II. Results from the immunohistochemistry analysis.

\begin{tabular}{|c|c|c|c|c|c|c|}
\hline Patient & Tissue type & Gender & AJCC & Fuhrman & DKK-1 & DKK-3 \\
\hline 1 & $\begin{array}{l}\text { Tumor tissue } \\
\text { Adjacent normal tissues }\end{array}$ & Male & III & III & $\begin{array}{c}+ \\
+++\end{array}$ & $\begin{array}{c}++ \\
+++\end{array}$ \\
\hline 2 & $\begin{array}{l}\text { Tumor tissue } \\
\text { Adjacent normal tissues }\end{array}$ & Male & IV & III & $\begin{array}{c}+ \\
++\end{array}$ & $\begin{array}{l}-/+ \\
++\end{array}$ \\
\hline 3 & $\begin{array}{l}\text { Tumor tissue } \\
\text { Adjacent normal tissues }\end{array}$ & Male & III & II & $\begin{array}{c}++ \\
+++\end{array}$ & $\begin{array}{c}++ \\
++++\end{array}$ \\
\hline 4 & $\begin{array}{l}\text { Tumor tissue } \\
\text { Adjacent normal tissues }\end{array}$ & Female & III & II & $\begin{array}{c}+ \\
+++\end{array}$ & $\begin{array}{c}+ \\
+++\end{array}$ \\
\hline 5 & $\begin{array}{l}\text { Tumor tissue } \\
\text { Adjacent normal tissues }\end{array}$ & Male & II & II & $\begin{array}{c}+ \\
++\end{array}$ & $\begin{array}{c}++ \\
+++\end{array}$ \\
\hline 6 & $\begin{array}{l}\text { Tumor tissue } \\
\text { Adjacent normal tissues }\end{array}$ & Female & II & I & $\begin{array}{l}-/+ \\
++\end{array}$ & $\begin{array}{l}-/+ \\
++\end{array}$ \\
\hline
\end{tabular}

$(-/+), 0-10 \% ;(+), 10-25 \% ;(++), 25-50 \% ;(+++), 50-75 \%$; and (++++), >75\% positive. AJCC, American Joint Committee on Cancer staging system, DKK, Dickkopf.

A

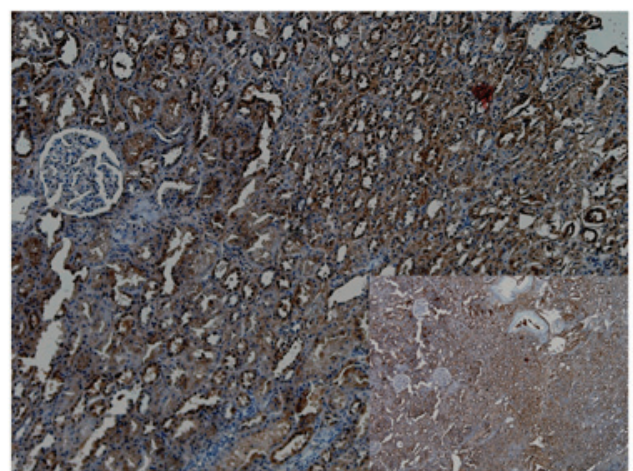

C

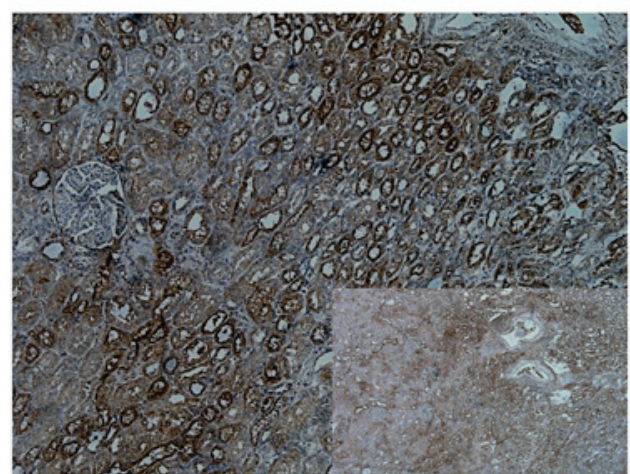

B
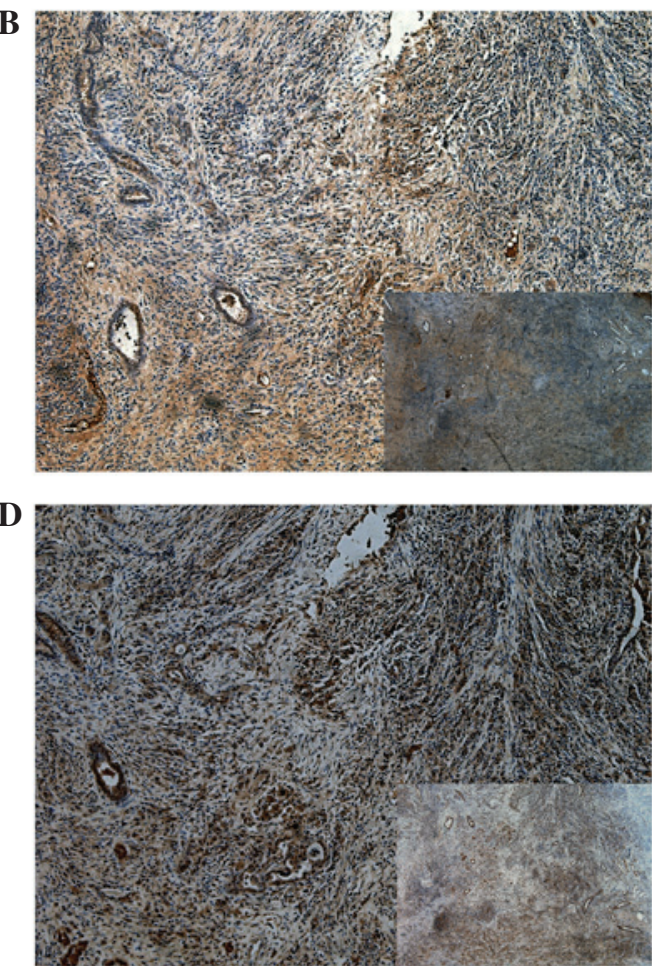

Figure 3. Expression of Dickkopf (Dkk)1 and Dkk3 in clear cell renal cell carcinoma (ccRCC) tumor tissues. (A) Dkk1 expression in adjacent normal tissues (magnification, x200; insert magnification, x40). (B) Dkk1 expression in tumor tissues (magnification, $\mathrm{x} 200$; insert magnification, $\mathrm{x} 40$ ). (C) Dkk3 expression in adjacent normal tissues (magnification, x200; insert magnification, x40). (D) Dkk3 expression in tumor tissues (magnification, x200; insert magnification, x40).

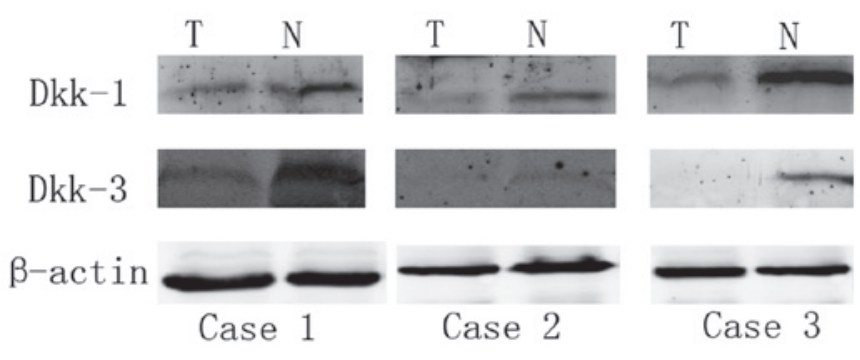

Figure 4. Western blot analysis of Dickkopf (Dkk)1 and Dkk3 in clear cel renal cell carcinoma (ccRCC). $\beta$-actin was used as an internal control. $\mathrm{N}$, adjacent normal tissues; $\mathrm{T}$, tumor tissues.

\section{Discussion}

Aberrant activation of the Wnt signaling pathway is a major characteristic of numerous types of cancer in humans, including colorectal cancer melanoma, non-small cell lung cancer, leukemia and bladder cancer (21). Recently, the Wnt signaling pathway has been investigated at several molecular levels, as its involvement has been indicated in tumorigenesis and disease progression. ccRCC is the most common histological type of RCC, and the Wnt signaling pathway has been indicated to have a significant role in the pathogenesis and progression of ccRCC. 

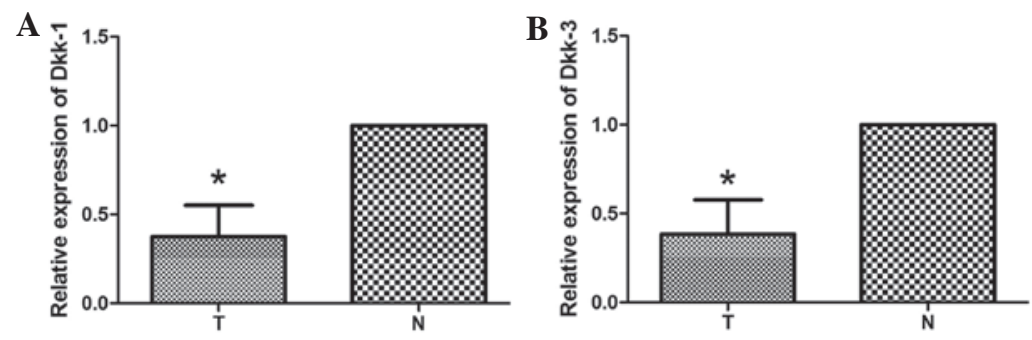

Figure 5. Expression of Dickkopf (Dkk)1 and Dkk3 in clear cell renal cell carcinoma (ccRCC) tissue and adjacent normal tissue, as detected by qPCR (A) Relative expression of Dkk1 in tumor tissue compared with normal tissue. (B) Relative expression of Dkk3 in tumor tissue compared with normal tissue. $\mathrm{N}$, adjacent normal tissues; $\mathrm{T}$, tumor tissues. ${ }^{*} \mathrm{P}<0.05$ vs. $\mathrm{N}$.

Previous trials have investigated the Wnt signaling pathway in order to develop novel cancer therapeutics for ccRCC $(22,23)$. Studies have shown that the secreted Wnt antagonist Dkk and its regulators may contribute to the diagnosis of human cancer, in addition to providing novel therapeutic targets (7,24-26).

It is well known that Dkk1 affects Wnt signaling either physically or functionally by interacting with LRP5 and LRP6. Dkk proteins also bind to Krm1 and Krm2, other single-pass transmembrane receptors. When Dkk binds to $\mathrm{Krm}$, a $\mathrm{Dkk} / \mathrm{LRP} / \mathrm{Krm}$ protein complex forms, which is endocytosed rapidly. The result of this action is the removal of LRP5/6 receptors from the cell membrane. The cell membrane is thus depleted of LRP receptors, and Wnt signaling is inhibited to a greater extent and for longer (27). Previous studies have shown that the expression of Dkk1 is downregulated in human colon cancer, gastric cancer and melanoma tissues, indicating that Dkk1 may act as a tumor suppressor in these types of cancer and not as an antagonist of Wnt signaling $(13,14,28,29)$. However, Dkk1 has been found to be overexpressed in hepatoblastoma and hepatocellular carcinoma, indicating that Dkk1 may be regulated by a feedback loop activated by the Wnt signaling pathway. These previous studies demonstrated that the function of Dkk1 may differ depending on the tissue of origin. In the present study, serum Dkk1 levels were found to be lower in the patients with ccRCC compared with the controls. Serum Dkk1 levels were also associated with AJCC stage and Fuhrman grade, indicating that Dkk1 may be used as a novel marker for the diagnosis, staging and prognosis of ccRCC. However, Urakami et al (17) found that the limited sensitivity and specificity of the Wnt antagonist genes meant that none of them could be used as a single reliable biomarker of RCC. One important reason for this was that only the levels of methylated DNA were assessed in the study and not the protein levels. Furthermore, in the present study, it was demonstrated using immunohistochemistry, western blot analysis and qPCR that Dkk1 levels in the tumor tissue were lower compared with those in the adjacent normal tissue. This indicates that Wnt signaling pathway activation may partially occur due to the functional loss of Wnt antagonists, and that carcinogenesis may result due to the dysregulation of cell proliferation and differentiation. It also indicates that Dkk1 may be used as a therapeutic target in the management of ccRCC. Hypermethylation of the Wnt antagonist genes has also been investigated in previous studies $(25,30,31)$, and promoter methylation of certain Wnt antagonists has been recognized as a strong prognostic marker for a poor outcome in patients with primary kidney cancer (17). In the present study, the meth- ylation of Dkk1 promoter was not investigated; however, the expression of Dkk1 in the tumor tissue was found to be lower compared with that in the adjacent normal tissue. This may be the result of the methylation of the Dkk1 promoter.

Dkk3 is the most divergent member of the human Dkk family. A previous study showed that Dkk3 regulates canonical Wnt signaling in lung cancer (32). It has also been demonstrated that Dkk3 has no effect on Wnt/ $\beta$-catenin signaling in prostate cancer cells, but instead induces apoptosis through the non-canonical c-Jun N-terminal kinase pathway $(33,34)$. Ueno et al $(16)$ reported that Dkk3 expression was regulated by histone modifications in the Dkk3 promoter region in RCC cells. Furthermore, the study showed that Dkk3 expression induced $\mathrm{G}_{0} / \mathrm{G}_{1}$ cell cycle arrest and decreased cell growth in RCC cells through p21 expression. This indicates that Dkk3 acts as a tumor suppressor in kidney cells and that the downregulation of $\mathrm{Dkk} 3$ may be involved in RCC progression (16). The expression of Dkk3 has been analyzed in several types of malignancies, and downregulation of Dkk3 has been observed in glioma, breast cancer, melanoma, prostate cancer and gastrointestinal cancer $(14,35$ 38). Further studies have revealed that the downregulation of Dkk3 in cancer was a result of epigenetic silencing by DNA methylation (17). It also has been reported that transfection of Dkk3 in certain tumor cells affected their invasive capacity and led to cell apoptosis, indicating that Dkk3 may act as a tumor suppressor $(14,32,34,39,40)$. However, Dkk3 mutant mice showed no enhanced tumorigenesis (41). By contrast, Dkk3 has been found to be overexpressed in hepatoblastoma and hepatocellular and esophageal squamous cell carcinoma. One possible reason may be due to an inactive form of Dkk3 in these tumors or an alteration of Dkk3 activity depending on cell type (40). Kurose et al (23) demonstrated that the decrease in the mRNA and protein levels of reduced expression in immortalized cells/Dkk-3 was observed irrespective of tumor grade and stage. In the present study, Dkk3 levels were analyzed using immunohistochemistry, western blotting and qPCR, and were found to be lower in the tumor tissue compared with the adjacent normal tissue. This was consistent with the results found by Kurose et al (23). Furthermore, in the present study, serum Dkk3 levels were found to be decreased in the patients with ccRCC compared with those in the controls. However, serum Dkk3 levels were not associated with AJCC stage and Fuhrman grade. Furthermore, the results demonstrated that Dkk3 expression was correlated with Dkk1 expression, indicating that Dkk3 and Dkk1 may have an associated mechanism in the development of ccRCC. 
To the best of our knowledge, this is the first study to investigate the expression levels of Dkk1 and Dkk3 in the serum and tumor specimens of patients with ccRCC, as well as their correlation with clinicopathological features. However, there were certain limitations to the study. Firstly, the number of patients analyzed was small $(n=64)$. Secondly, the detailed mechanism of the action of the Dkk family in ccRCC was not investigated. Furthermore, the correlation between Dkk serum level and the prognosis of ccRCC was not investigated.

In conclusion, a decrease in Dkk1 and Dkk3 mRNA and protein levels was observed in the ccRCC tissues. The serum Dkk1 and Dkk3 levels in the patients with ccRCC were found to be significantly lower than those in the controls, and the Dkk1 levels were associated with the clinicopathological features of the ccRCC patients. Consequently, Dkk1 and Dkk3 may present a novel molecular target for the diagnosis and treatment of ccRCC. However, the detailed mechanisms behind the actions of the Dkk family in ccRCC require further investigation.

\section{References}

1. Rini BI, Campbell SC and Escudier B: Renal cell carcinoma Lancet 373: 1119-1132, 2009

2. Deng FM, Melamed J and Zhou M: Pathology of renal cell carcinoma. In: Renal Cancer. Libertino JA (ed). Springer New York, NY, pp51-69, 2013.

3. Vacas E, Bajo AM, Schally AV et al: Vasoactive intestinal peptide induces oxidative stress and suppresses metastatic potential in human clear cell renal cell carcinoma. Mol Cell Endocrinol 365: 212-222, 2013

4. Escudier B, Szczylik C, Porta C and Gore M: Treatment selection in metastatic renal cell carcinoma: expert consensus. Nat Rev Clin Oncol 9: 327-337, 2012.

5. Cohen ED, Tian Y and Morrisey EE: Wnt signaling: an essential regulator of cardiovascular differentiation, morphogenesis and progenitor self-renewal. Development 135: 789-798, 2008.

6. Klaus A and Birchmeier W: Wnt signalling and its impact on development and cancer. Nat Rev Cancer 8: 387-398, 2008.

7. Veeck $\mathbf{J}$ and Dahl E: Targeting the Wnt pathway in cancer: the emerging role of Dickkopf-3. Biochim Biophys Acta 1825: 18-28, 2012 .

8. Mao B, Wu W, Li Y, et al: LDL-receptor-related protein 6 is a receptor for Dickkopf proteins. Nature 411: 321-325, 2001.

9. Patil MA, Chua MS, Pan KH, et al: An integrated data analysis approach to characterize genes highly expressed in hepatocellular carcinoma. Oncogene 24: 3737-3747, 2005.

10. Wirths O, Waha A, Weggen S, et al: Overexpression of human Dickkopf-1, an antagonist of wingless/WNT signaling, in human hepatoblastomas and Wilms' tumors. Lab Invest 83: 429-434, 2003.

11. Takahashi N, Fukushima T, Yorita K, Tanaka H, Chijiiwa K and Kataoka H: Dickkopf-1 is overexpressed in human pancreatic ductal adenocarcinoma cells and is involved in invasive growth. Int J Cancer 126: 1611-1620, 2010.

12. Shizhuo W, Tao J, Shulan Z and Bing Z: The expression and significance of Dickkopf-1 in epithelial ovarian carcinoma. Int J Biol Markers 24: 165-170, 2009.

13. González-Sancho JM, Aguilera O, García JM, et al: The Wnt antagonist DICKKOPF-1 gene is a downstream target of beta-catenin/TCF and is downregulated in human colon cancer. Oncogene 24: 1098-1103, 2005.

14. Kuphal S, Lodermeyer S, Bataille F, Schuierer M, Hoang BH and Bosserhoff AK: Expression of Dickkopf genes is strongly reduced in malignant melanoma. Oncogene 25: 5027-5036, 2006.

15. Livark, KJ and Schmittgen TD: Analysis of relative gene expression data using real-time quantitative PCR and the 2(-Delta Delta C(T)) method. Methods 25: 402-408, 2001.

16. Ueno K, Hirata H, Majid S, et al: Wnt antagonist DICKKOPF-3 (Dkk-3) induces apoptosis in human renal cell carcinoma. Mol Carcinog 50: 449-457, 2011.

17. Urakami S, Shiina H, Enokida H, et al: Wnt antagonist family genes as biomarkers for diagnosis, staging, and prognosis of renal cell carcinoma using tumor and serum DNA. Clin Cancer Res 12: 6989-6997, 2006
18. Sobin LH, Gospodarowicz MK and Wittekind C (eds): International Union Against Cancer (UICC) TNM Classification of Malignant Tumours. 7th edition. Wiley-Liss, New York, NY, pp1-336, 2009.

19. Edge SB, Byrd DR, Compton CC, Fritz AG, Greene FL and Trotti A (eds): American Joint Committee on Cancer (AJCC). AJCC Cancer Staging Manual. 7th edition. Springer-Verlag, New York, NY, pp1-649, 2010.

20. Winer J, Jung CK, Shackel I and Williams PM: Development and validation of real-time quantitative reverse transcriptase-polymerase chain reaction for monitoring gene expression in cardiac myocytes in vitro. Anal Biochem 270: 41-49, 1999.

21. Anastas JN and Moon RT: WNT signalling pathways as therapeutic targets in cancer. Nat Rev Cancer 13: 11-26, 2013.

22. Forget MA, Turcotte S, Beauseigle D, et al: The Wnt pathway regulator DKK1 is preferentially expressed in hormone-resistant breast tumours and in some common cancer types. $\mathrm{Br} \mathrm{J}$ Cancer 96: 646-653, 2007.

23. Kurose K, Sakaguchi M, Nasu Y, et al: Decreased expression of REIC/Dkk-3 in human renal clear cell carcinoma. J Urol 171: 1314-1318, 2004

24. Jiang T, Huang L and Zhang S: DKK-1 in serum as a clinical and prognostic factor in patients with cervical cancer. Int J Biol Markers 28: 221-225, 2013

25. Urakami S, Shiina H, Enokida $\mathrm{H}$, et al: Combination analysis of hypermethylated Wnt-antagonist family genes as a novel epigenetic biomarker panel for bladder cancer detection. Clin Cancer Res 12: 2109-2116, 2006.

26. Jin Y, Murata H, Sakaguchi M, et al: Partial sensitization of human bladder cancer cells to a gene-therapeutic adenovirus carrying REIC/Dkk-3 by downregulation of BRPK/PINK1. Oncol Rep 27: 695-699, 2012.

27. Niehrs C: The complex world of WNT receptor signalling. Nat Rev Mol Cell Biol 13: 767-779, 2012.

28. Mikata R, Yokosuka O, Fukai K, et al: Analysis of genes upregulated by the demethylating agent 5-aza-2'-deoxycytidine in gastric cancer cell lines. Int J Cancer 119: 1616-1622, 2006.

29. Niida A, Hiroko T, Kasai M, et al: DKK1, a negative regulator of Wnt signaling, is a target of the beta-catenin/TCF pathway. Oncogene 23: 8520-8526, 2004.

30. Hsieh SY, Hsieh PS, Chiu CT and Chen WY: Dickkopf-3/REIC functions as a suppressor gene of tumor growth. Oncogene 23: 9183-9189, 2004.

31. Fukui T, Kondo M, Ito G, et al: Transcriptional silencing of secreted frizzled related protein 1 (SFRP 1) by promoter hypermethylation in non-small-cell lung cancer. Oncogene 24: 6323-6327, 2005.

32. Yue W, Sun Q, Dacic S, et al: Downregulation of Dkk3 activates beta-catenin/TCF-4 signaling in lung cancer. Carcinogenesis 29: 84-92, 2008

33. Kawano Y, Kitaoka M, Hamada Y, Walker MM, Waxman J and Kypta RM: Regulation of prostate cell growth and morphogenesis by Dickkopf-3. Oncogene 25: 6528-6537, 2006.

34. Abarzua F, Sakaguchi M, Takaishi M, et al: Adenovirus-mediated overexpression of REIC/Dkk-3 selectively induces apoptosis in human prostate cancer cells through activation of c-Jun- $\mathrm{NH}_{2}$-kinase. Cancer Res 65: 9617-9622, 2005.

35. Mizobuchi Y, Matsuzaki K, Kuwayama K, et al: REIC/Dkk-3 induces cell death in human malignant glioma. Neuro Oncol 10: 244-253, 2008

36. Kloten V, Becker B, Winner K, et al: Promoter hypermethylation of the tumor-suppressor genes ITIH5, DKK3, and RASSF1A as novel biomarkers for blood-based breast cancer screening. Breast Cancer Res 15: R4, 2013.

37. Zenzmaier C, Sampson N, Plas E and Berger P: Dickkopf-related protein 3 promotes pathogenic stromal remodeling in benign prostatic hyperplasia and prostate cancer. Prostate 73: 14411452,2013

38. Than SS, Kataoka K, Sakaguchi M, et al: Intraperitoneal administration of an adenovirus vector carrying REIC/Dkk-3 suppresses peritoneal dissemination of scirrhous gastric carcinoma. Oncol Rep 25: 989-995, 2011.

39. Koppen A, Ait-Aissa R, Koster J, et al: Dickkopf-3 expression is a marker for neuroblastic tumor maturation and is down-regulated by MYCN. Int J Cancer 122: 1455-1464, 2008.

40. Hoang BH, Kubo T, Healey JH, et al: Dickkopf 3 inhibits invasion and motility of Saos-2 osteosarcoma cells by modulating the Wnt-beta-catenin pathway. Cancer Res 64: 2734-2739, 2004.

41. Barrantes Idel B, Montero-Pedrazuela A, Guadaño-Ferraz A, et al: Generation and characterization of dickkopf 3 mutant mice. Mol Cell Biol 26: 2317-2326, 2006. 